Tito Sena

Universidade Federal de Santa Catarina

\title{
Os relatórios Masters \& Johnson: gênero e as práticas psicoterapêuticas sexuais a partir da década de $70^{1}$
}

\begin{abstract}
Resumo: Este trabalho é o resultado de uma análise sobre os relatórios Masters \& Johnson, editados originalmente nos anos de 1966 (A Resposta Sexual Humana) e 1970 (A Inadequação Sexual Humana). Os relatórios analisados, produzidos nos Estados Unidos e com repercussão mundial, foram elaborados a partir de uma minuciosa investigação científica das respostas fisiológicas e anatômicas da sexualidade masculina e feminina. Os autores, em decorrência, utilizaram esses conhecimentos para a formulação de técnicas e tratamento em terapia sexual utilizadas até hoje por profissionais da área clínica. Os relatórios Masters \& Johnson emergiram com a proposta de preencher as lacunas médicas, fisiológicas e psicológicas diante das pesquisas estatísticas comportamentais de Alfred Kinsey (1948 e 1953). A obra de M\&J se apresenta abertamente como uma defesa do casamento monogâmico heterossexual, e com elaborações atravessadas por questões de gênero. Partindo do instrumental teórico de Michel Foucault, verifica-se serem exemplares da prática de uma scientia sexualis, que procura instituir uma verdade no sexo e do sexo.
\end{abstract}

Palovras-chave: relatórios Masters \& Johnson; sexualidade; terapia sexual.

Copyright (C) 2010 by Revista Estudos Feministas.

' Este artigo teve origem em capítulo da tese de doutorado intitulada Os relatórios Kinsey, Masters \& Johnson, Hite: as sexualidades estatísticas em uma perspectiva das ciências humanas, defendida pelo autor no Programa de Pós-Graduação Interdisciplinar em Ciências Humanas da Universidade Federal de Santa Catarina, em 2007.

${ }^{2}$ A WAS - Associação Mundial de Sexologia, fundada em 1978, é destinada ao intercâmbio interna-

\section{Introdução}

A sexologia é um campo teórico e prático com status de ciência entre estudiosos de diversas áreas, sem especificamente formar uma disciplina tradicionalmente acadêmica, transitando em proximidade com Medicina, Psicologia, Antropologia, Biologia, Sociologia, Direito e outros saberes. Não obstante, a sexologia é marcada por duas tendências: uma funcional, mais biológica, portanto médica; e outra antropológica, mais cultural e social.

Os levantamentos da WAS ${ }^{2}$ - Word Association for Sexology apontam que no mundo $20 \%$ dos sexólogos são médicos e os outros $80 \%$ são de várias áreas. Não obstante, 
cional e cultural do conhecimento científico e social sobre a sexualidade, reunindo 68 organizações representantes de 32 países de todos os continentes, mantendo vínculos com a OMS e a UNESCO. No XIV Congresso Mundial de Sexologia, promovido pela WAS, em Hong Kong, em 1999, foi elaborada a Declaração dos Direitos Sexuais. (Fonte: disponível em htpp// www.worldsexology.org, com acesso em 28 jan. 2007.)

${ }^{3}$ No Brasil, houve uma situação, no mínimo, curiosa em relação aos domínios profissionais: em 1980, o Conselho Federal de Medicina reconheceu a sexologia como especialidade médica, através da Resolução 1.019/1980 e referendada pela Resolução 1.441 , de 12 de agosto de 1994. Posteriormente, o mesmo CFM incluiu a sexologia como área de atuação da ginecologia e urologia, segundo a Resolução 1.634/ 2002.

${ }^{4}$ Os relatórios Kinsey - O comportamento sexual do homem (1948) e O comportamento sexual da mulher (1953) - também foram objetos da pesquisa, mas neste artigo não serão explorados.

${ }^{5}$ MASTERS e JOHNSON, 1984, p. 3-4, grifos meus.
$80 \%$ dos psicólogos associados são também sexólogos. No Brasil, segundo a SBRASH - Sociedade Brasileira da Sexualidade Humana, os dados se invertem com $58 \%$ sendo médi$\cos ^{3}$ e $42 \%$ psicólogos.

A sexologia contemporânea, médica e/ou psicológica, tem no casal Masters \& Johnson referência fundamental, tanto como recurso para avaliações de disfunções sexuais, como para técnicas de tratamento em terapia sexual.

A pesquisa do ginecologista William Howell Masters (1915-2001) e da psicóloga Virginia Eshelman Johnson (1925-) iniciou-se em 1954, na Universidade de Washington, no ano seguinte à publicação do relatório Sexual Behavior in the Humam Female, com o objetivo de preencher, segundo suas palavras, uma lacuna específica deixada por Alfred Kinsey e seus relatórios. ${ }^{4}$ Masters decidiu efetuar seus estudos por julgar o relatório de seu compatriota essencialmente sociológico, e por ter deixado em aberto importantes questões de natureza fisiológica. Não obstante, Masters \& Johnson confirmaram muitas descobertas de Kinsey e acrescentaram outras, como a de que o tamanho do pênis não tem nenhuma relação com o desempenho sexual e a de que não existe orgasmo vaginal em oposição ao orgasmo clitoriano (divisão sustentada por Freud na teoria psicanalítica).

Kinsey e colaboradores apresentaram uma compilação monumental de estatísticas contendo padrões de procedimento sexual nos Estados Unidos, de 1938 a 1952. Esses relatórios de práticas sexuais humanas, obtidos através de técnicas de interrogatório direto, oferecem uma base inestimável de informação sociológica. [...] Embora o trabalho de Kinsey tenha se tornado um marco da pesquisa sociológica, não foi projetado para interpretar a resposta fisiológica ou psicológica ao estímulo sexual. ${ }^{5}$

O primeiro texto de Masters \& Johnson, Human Sexual Response (A Resposta Sexual Humana), publicado em 1966 nos Estados Unidos, foi o resultado de investigações laboratoriais das reações fisiológicas e anatômicas de 694 voluntários (312 homens e 382 mulheres), após o acompanhamento de 10 mil relações sexuais em 11 anos de estudo. O segundo relatório, Human Sexual Inadequacy (A Inadequação Sexual Humana), foi resultado de trabalhos clínicos, tendo sido publicado em 1970, 11 anos após a criação, em 1959, de um programa de pesquisa clínica especializada no tratamento de disfunções sexuais, em que 790 pessoas foram atendidas pelos serviços terapêuticos dos autores. Muito embora o segundo texto se baseie em trabalhos clínicos, o casal Masters \& Johnson utilizou-se das descobertas dos estudos laboratoriais (publicados no primeiro texto) para os tratamentos psicoterapêuticos. 
${ }^{6}$ William Masters se divorciou de Virginia Johnson em 1993, e se retirou para sua residência no Arizona em 1994, aos 78 anos, quando apresentava sinais iniciais da doença de Parkinson. A evolução da doença exigiu cuidados médicos nos anos que antecederam sua morte, aos 85 anos, em fevereiro de 2001. (Fonte: disponível em http:// obits.com/masterswilliamh.html, acessado e baixado em 9 jan. 2004.) O casal, além dos relatórios, publicou vários artigos e livros, tais como O Vínculo do prazer, Homossexualidade em perspectiva, Heterossexualidade, Manual de Medicina Sexual, etc. (arrolados nas referências bibliográficas)
Em 1964, o casal fundou o Instituto Masters \& Johnson, em St. Louis, Missouri, para atividades de pesquisas e terapêuticas, sendo essa instituição fechada em $1994 .{ }^{6}$

No Brasil, os volumes foram publicados pela editora Civilização Brasileira, ambos com títulos em tradução não correspondentes às edições norte-americanas: o primeiro relatório, A Conduta Sexual Humana, em 1969 (três anos após a edição dos Estados Unidos); e o segundo, $A$ Incompetência Sexual, em 1970. Mais tarde, a editora Roca reeditou-os com títulos corretos: A Resposta Sexual Humana, em 1984, e A Inadequação Sexual Humana, em 1985.

\section{A Resposta Sexual Humana (1966)}

O primeiro livro de Masters \& Johnson, Human Sexual Response (A Resposta Sexual Humana), foi publicado em 1966 após 11 anos de estudos laboratoriais centrados na fisiologia e anatomia da resposta sexual masculina e feminina. A publicação está formatada com o seguinte índice:

- PESQUISA SOBRE A RESPOSTA SEXUAL

1. O Ciclo da Resposta Sexual

2. A População Pesquisada

- A RESPOSTA SEXUAL FEMININA

3. Resposta Extragenital Feminina

4. Genitália Externa Feminina - Anatomia e Fisiologia

5. O Clitóris

1. Anatomia e Fisiologia

2. Considerações Clínicas

6. A vagina

1. Anatomia e Fisiologia

2. O Papel Funcional na Reprodução

3. A Vagina como Órgão Reprodutor

7. A Vagina Artificial - Anatomia e Fisiologia

8. O Útero - Considerações Fisiológicas e Clínicas

9. O Orgasmo Feminino

10. Gravidez e Resposta Sexual

1. Anatomia e Fisiologia

2. Considerações Clínicas

- A RESPOSTA SEXUAL MASCULINA

11. Reações Extragenitais Masculinas

12. O Pênis

1. Anatomia e Fisiologia

2. Considerações Clínicas

13. O Escroto e os Testículos - Anatomia e Fisiologia

14. O Orgasmo Masculino (Ejaculação) 
- RESPOSTA SEXUAL GERIÁTRICA

15. A Mulher Idosa

1. Anatomia e Fisiologia

2. Considerações Clínicas

16. O Homem Idoso

1. Anatomia e Fisiologia

2. Considerações Clínicas

- GENERALIDADES NA RESPOSTA SEXUAL

17. Similaridades na Resposta Fisiológica

18. A Miotonia na Resposta Sexual

19. Amostragem Específica de Casos de Sexualidade

No prefácio do livro, Masters \& Johnson fazem reconhecimento a Kinsey, pela sua contribuição e esforço inacreditável em abrir as portas da objetividade investigadora na área da sexualidade. O texto, em linguagem médica, fisiológica e anatômica, está basicamente dividido em quatro capítulos: pesquisa sobre a resposta sexual, a resposta sexual feminina, a resposta sexual masculina e a resposta sexual geriátrica. Entretanto, seguramente estão dedicadas três vezes mais atenção para as descrições das reações femininas (1 14 páginas) do que das reações masculinas (40 páginas). Todas as seções contam com razoável material ilustrativo com figuras de seios, genitália, pelves em corte nas diversas fases de resposta sexual, radiografias, gráficos e medições eletródicas de contrações orgásmicas.

Para elaborar A Resposta Sexual Humana, Masters \& Johnson recorreram a um conjunto de procedimentos para a coleta de seus dados: interrogatórios extensos para levantamento do perfil médico, social e psicossexual dos sujeitos pesquisados, observações minuciosas diretas com uso de filmagens em cores, e estudos laboratoriais dos aspectos físicos e fisiológicos das relações sexuais. Foram utilizados também recursos como vagina artificial e pênis de plástico transparente, para observações de coitos artificiais através de técnicas radiofísicas, de iluminação e dispositivo fotográfico miniaturizado. Esse aparato sofisticado de equipamentos tecnológicos indicou uma ruptura nos procedimentos de investigação da sexualidade, pois a observação se tornou biológica e micrométrica, na coleta de mínimos detalhes geradores de explicações causais.

Numa primeira etapa do programa de sua pesquisa, Masters efetuou uma seleção inicial de indivíduos entre 118 prostitutas e 27 homens "prostituídos" (termo de Masters), que contaram suas histórias sociossexuais, ocupacionais e médicas. Desse grupo, 8 mulheres e 3 homens foram escolhidos para um estudo anatômico e fisiológico. Os critérios de seleção foram "inteligência não abaixo do 
7 MASTERS $\mathrm{J}$ JOHNSON, 1984, p. 10.

${ }^{8}$ MASTERS e JOHNSON, 1984, p. 10.

\begin{abstract}
${ }^{9}$ Lembrando que os testes de inteligência sempre foram estudados e valorizados nos Estados Unidos, sendo outro exemplo discursivo da ênfase na mensuração psicométrica, classificatória, enquadradora e hierarquizante das pessoas.
\end{abstract}

${ }^{10}$ MASTERS E JOHNSON, 1984. normal, experiência variada na prostituição, capacidade efetiva de expressão oral e, por certo, um grau consistentemente alto de disponibilidade de cooperação". ${ }^{7}$ Muito embora esse pequeno grupo tenha contribuído como matéria de estudo de laboratório, os resultados dos interrogatórios e experimentos com eles/elas não foram incluídos na pesquisa definitiva. Para William Masters,

Dois fatores influíram para essa decisão: 1) As tendências migratórias dessa população desencorajaram o registro dos padrões individuais da resposta sexual durante longos períodos de tempo; 2) Os vários graus de patologia dos órgãos de reprodução, usualmente presentes em população deste tipo, impediram a possibilidade do estabelecimento de uma linha básica segura para o estudo da normalidade anatômica. ${ }^{8}$

Masters, então, redirecionou sua amostragem populacional, dessa vez com a ajuda da psicóloga Virginia Johnson. Decidiu buscar voluntários de origem social, intelectual e econômica selecionada ("relativamente superiores"), ${ }^{9}$ de uma comunidade metropolitana, com chamamento público. Entretanto, no decorrer da pesquisa, outras fontes de recrutamento (universidades e ambulatórios) e formas de seleção foram se incorporando, tendo sido aceitos voluntários de todas as idades, de todas as camadas sociais e de qualquer nível educacional. Mesmo assim, houve o predomínio de pessoas com origem socioeconômica e educacional mais elevada. ${ }^{10}$

A população experimental foi sucessivamente sendo alterada, com alguns voluntários conservados durante alguns anos como membros ativos do grupo e outros substituídos. Uma das formas de avaliação sobre a permanência no grupo experimental foi a verificação das reações à estimulação sexual efetiva dos candidatos voluntários e de alterações diante do ambiente artificial de laboratório. Essa artificialidade constituiu-se numa preocupação constante de Masters \& Johnson, pois, mesmo com cuidados de presença discreta dos observadores, significava um fator preponderante para as avaliações.

O grupo experimental potencial recebia exame físico e, após aprovação médica, era incluído no grupo de cooperação ativa do programa e encaminhado aos alojamentos especiais, com garantia de anonimato. De um total de 1.273 pré-entrevistados, selecionaram-se para as observações laboratoriais 276 pares legalmente casados, 106 mulheres solteiras e 36 homens solteiros (ou seja, 694 pessoas, sendo 382 mulheres e 312 homens).

Importante destacar que, tendo participado um pequeno número de homens e mulheres negros/as, os resulta- 
11 Os relatórios Hite sobre a sexualidade feminina (1976) e sobre a sexualidade masculina (1981) compuseram os documentos da tese, mas, tal como com os relatórios Kinsey, não foram explorados neste artigo.

12 MASTERS e JOHNSON, 1984, p. 18, grifos meus.

${ }^{13} \mathrm{~A}$ sugestão de um modelo de fases de resposta sexual não foi pioneirismo de Masters \& Johnson. Wilhelm Reich, em O combate sexual da juventude, original de 1932, e em A função do orgasmo, de 1942, apresenta uma descrição e um diagrama mostrando as fases típicas (5) do ato sexual, em que homem e mulher são orgasticamente potentes: I) fase de controle voluntário da excitação; II) fase de contrações involuntárias; III) súbita ascensão ao clímax; IV) orgasmo; V) queda brusca de excitação (REICH, 1986 e 1995). M\&J, entretanto, não fazem alusão direta a Reich, mas o relacionam nas referências bibliográficas.

14 MASTERS e JOHNSON, 1984, $\mathrm{p}$ 113, grifos meus. dos da pesquisa são reconhecidos pelos próprios pesquisadores como atribuídos à raça branca.

Masters \& Johnson, muito embora tenham feito interrogatórios, deixam bem claro, numa diferenciação metodológica em relação a Kinsey (e também mais tarde em relação aos relatórios de Shere Hite), " sua opção por utilizar observações diretas:

Finalmente, e possivelmente o mais importante, é a informação recolhida em 11 anos de trabalho direto com homens e mulheres a responderem à estimulação sexual efetiva. Dever-se-ia ter constantemente no espírito que o primeiro interesse da pesquisa concentrou-se quase que literalmente sobre o que o homem e a mulher fazem em resposta á estimulação sexual efetiva, e porque o fazem, mais do que sobre - que as pessoas dizem que fazem, ou mesmo pensam no que poderiam ser suas reações e suas experiências sexuais. ${ }^{12}$

Se, por um lado, os procedimentos de observação foram considerados inovadores e ousados, por outro, críticas ou objeções poderiam ser levantadas sobre a pouca espontaneidade e artificialidade provavelmente presentes nas relações sexuais programadas.

A descoberta clínica significativa de M\&J, com aplicações atuais convalidadas por profissionais na área da psicoterapia sexual, foi o que eles denominaram a resposta sexual masculina e feminina, na forma de quatro fases sucessivas: ${ }^{13}$ 1) fase de excitamento; 2) fase platô; 3) fase do orgasmo; e 4) fase final ou de resolução. Essas fases são expostas em diagramas e descritas em mínimos detalhes quanto às reações vasocongestivas, musculares, contráteis e eretivas em diversas partes do corpo da mulher (seios, uretra, bexiga, reto, pequenos lábios, grandes lábios, vagina, clitóris e útero) e do homem (peito, reto, pênis, escroto, testículos). Com referência ao orgasmo feminino, M\&J se colocam da seguinte maneira:

Em nossa cultura, a obtenção do orgasmo pela mulher nunca atingiu a situação indiscutível de que goza a ejaculação masculina. Enquanto o orgasmo masculino (ejaculação) tem o papel reprodutor a sustentar a sua aceitação perpétua, está ainda para ser formulada uma referência equivalente com respeito ao orgasmo feminino. [...] Com a fisiologia orgásmica estabelecida, a mulher tem agora uma oportunidade inegável para desenvolver realisticamente os seus próprios níveis de resposta sexual. A disseminação deste ato capacita o homem para contribuir com a sua parte no desenvolvimento dessa idéia como suporte de uma relação efetiva, no seio da unidade conjugal..$^{14}$ 


\begin{abstract}
${ }^{15}$ Essa classificação de M\&J aponta para a necessidade de uma cuidadosa análise da variável etária, tendo em conta que as alterações na expectativa de vida no século $X X$ foram substanciais, e uma comparação com essa recontextualização histórica evidencia a transformação dos conceitos de velhice (e juventude) de uma época e cultura.
\end{abstract}

O relatório aborda também as generalidades e similaridades existentes nas respostas masculinas e femininas aos estímulos sexuais, como o rubor sexual, a miotonia (tensão muscular), hiperventilação, taquicardia, pressão sanguínea e reação perspiratória (reação sudorípara).

Para finalizar, o capítulo sobre a resposta sexual geriátrica (acima de 50 anos) ${ }^{15}$ mantém a mesma sistemática de apresentação dos resultados das fases das reações anatômicas e fisiológicas, distinguindo-se, porém, as mulheres pelas condições etárias de estarem na menopausa.

\section{A Inadequação Sexual Humana (1970)}

O segundo livro de Masters \& Johnson, Human Sexual Inadequacy (A Inadequação Sexual Humana), foi editado em 1970, após quatro anos da publicação de Human Sexual Response, contendo 15 capítulos distribuídos de acordo com o seguinte índice:
I. Conceitos de terapia
II. Formas de terapia
III. Ejaculação prematura
IV. Incapacidade ejaculatória
V. Impotência primária
VI. A impotência secundária
VII. O tratamento da impotência
VIII. Disfunção orgásmica
IX. Vaginismo
$X$. Dispareunia
XI. Tratamento da disfunção orgásmica
XII. A insuficiência sexual do homem idoso
XIII. Insuficiência sexual da mulher idosa
XIV. Estatística do programa
XV. Fracassos no tratamento

O prefácio de A Inadequação Sexual Humana aponta este segundo texto como sendo a aplicação clínica das disciplinas científicas da anatomia e fisiologia humanas exploradas no primeiro livro, o pré-clinico A Resposta Sexual Humana. Os dois livros, portanto, se complementam para a prevenção de "problemas de disfunção sexual". O casal aponta para imprecisões no seu trabalho, merecedor de aperfeiçoamentos futuros:

Este texto clínico tem inúmeras deficiências em conceito e conteúdo - população estatisticamente limitada e, do ponto de vista da motivação, predisposta; trabalho imperfeito de acompanhamento subseqüente dos pacientes durante cinco anos; alterações não comprovadas dos conceitos básicos de psicoterapia; 
${ }^{16}$ MASTERS e JOHNSON, 1976, p. xiii, grifos meus.
${ }^{17}$ MASTERS e JOHNSON, 1976, p. e incapacidade de descrever precisamente as sutilezas tão vitais para o rendimento eficaz do tratamento - são alguns dos exemplos. Não há dúvida de que este relatório terá pouco valor, a menos que o conceito e o conteúdo sejam, no futuro, fortalecidos pelo êxito de grande número de equipes masculinofemininas em várias áreas geográficas do mundo inteiro. ${ }^{16}$

Fica evidente, dessa maneira, o caráter propositivo universalista de M\&J para o tratamento, com suas formulações psicoterapêuticas submetidas a avaliações confirmatórias posteriores por parte dos profissionais clínicos, especialmente os terapeutas sexuais e sexólogos.

O tratamento era realizado segundo um rigoroso programa. No início, unidades conjugais dedicavam três semanas ao programa terapêutico, com isolamento social e exposição, diária e intensa, a questões sexuais, com a realização de conferências, entrevistas, conversas, consultas, sessões, interrogatórios, avaliações de diagnóstico e prognóstico, anamneses (histórico da queixa), etc. Após o término dessa fase de tratamento rápido e crítico do programa, iniciavase um acompanhamento quinquenal.

Constituíram-se para os tratamentos 510 unidades conjugais ( 287 unidades com queixa unilateral e 223 unidades com queixas bilaterais) e 57 unidades simples (54 homens e 3 mulheres), com encaminhamentos dos pacientes promovidos por "autoridades", consideradas estas as funções de médico, psicólogo, assistente social e teólogo. Foram tratados 790 indivíduos no período de controle de 11 anos e, destes, $73 \%$ tinham curso superior completo ou incompleto.

Uma das premissas básicas desenvolvidas ao longo do texto é: "embora tanto o marido quanto a mulher, num casamento onde há disfunção sexual, devam ser tratados, a relação conjugal entre eles é que é o paciente". ${ }^{17}$ Ou seja, o problema é da unidade conjugal, do casal, e não um problema individual, pessoal, de um dos cônjuges.

A abordagem terapêutica da Reproductive Biology Research Foundation, antecessora do Instituto Masters \& Johnson, tem algumas peculiaridades para a investigação clínica da insuficiência sexual, como, por exemplo, o método de coterapia. Nele é formada uma equipe masculino-feminina de terapeutas, cada um encarregado de procedimentos e responsabilidades avaliatórios, interpretativos e representativos para o membro do sexo masculino ou feminino da unidade conjugal. Esse recurso é assim justificado por M\&J:

O papel de intérprete não constitui a contribuição total que um coterapeuta proporciona ao aceitar a principal responsabilidade de representação ligada 
${ }^{18}$ MASTERS e JOHNSON, 1976, p. 8.

${ }^{19}$ Considerando-se o movimento das sufragistas no início do século $\mathrm{XX}$ como a $1^{\mathrm{a}}$ onda do feminismo, as forças contestatórias, sociais e políticas da $2^{a}$ onda têm alguns marcos discursivos - as obras $A$ mística feminina (1963), de Betty Friedan, Políticas sexuais (1970), de Kate Millet, $A$ mulher eunuco (1970), de Germaine Greer, $A$ dialética do sexo (1970), de Shulamith Firestone, e Psicanálise e feminismo (1974), de Juliet Mitchell, são exemplos clássicos. Importante destacar que os relatórios M\&J (1966 e 1970) foram editados nesse mesmo contexto histórico, embora tenham levado mais de 11 anos de estudos.

${ }^{20}$ MASTERS e JOHNSON, 1976, p. 87, grifos meus. ao sexo. O coterapeuta masculino pode oferecer à mulher da unidade conjugal atribulada muita informação relativa à função sexual do homem; e, o que é igualmente importante, o material de orientação feminina é melhor expressado ao marido pelo coterapeuta feminino. [...] Uma equipe masculina-feminina evita a desvantagem terapêutica potencial de se interpretar queixas do paciente baseadas em prevenção masculina e feminina. ${ }^{18}$

Pode-se sintetizar a proposta de intervenção do casal M\&J como biológica, educacional e behaviorista (comportamentalista), buscando na anamnese psicossexual-social as informações necessárias para os procedimentos terapêuticos. O interrogatório estandartizado é estratégia fundamental para o processo de verificação das atitudes, sentimentos, valores, expectativas e experiências do sistema sexual. Sempre lembrando a diretriz de o foco da terapia ser o casal, a unidade conjugal, M\&J expressam uma questão de gênero que as feministas ${ }^{19}$ passariam a explorar discursivamente como uma bandeira reivindicatória - o seu prazer -, conforme expresso nesta passagem:

O mais desastroso falso conceito que nossa cultura deu à função sexual é a suposição, por parte de homens e mulheres, de que os homens, por orientação divina e por instinto infalível, são capazes de discernir exatamente o que uma mulher deseja sexualmente, e quando o deseja. [...] $\bigcirc$ segundo engano sexual freqüentemente encontrado, sendo por conseguinte um repressivo constante à expressão sexual eficaz, é a suposição, também por parte dos homens e mulheres, de que a perícia sexual é da responsabilidade do homem. Na verdade, mulher alguma pode saber a que tipo de prazer sexual ela reagirá em qualquer oportunidade determinada, até que confrontada com a ausência de um fator estimulativo particu-larmente desejado. ${ }^{20}$

Um outro recurso utilizado na terapêutica, bastante polêmico e atravessado por gênero, é o uso de parceira/o substituta/o e parceira sub-rogada. Essa cooperação era sugerida preferencialmente, mas não unicamente, para homens solteiros encaminhados com disfunção sexuais. A/o parceira/o substituta/o era escolhida/o pelo paciente, trazida/o pelo homem ou mulher para auxílio orientado na solução do problema de terapia clínica; a parceira subrogada é indicada pelos coterapeutas, diante de não se dispor de uma mulher escolhida pelo próprio paciente homem. M\&J manifestam serem contrários à escolha de parceiro sub-rogado para a mulher sexualmente insuficiente, justificando a aparente aplicação de um duplo padrão de tratamento clínico da seguinte forma: 
${ }^{21}$ MASTERS e JOHNSON, 1976, p. 154, grifos meus.

22 Incluem-se nessas disfunções sexuais masculinas: a impotência primária, definida como aquela que ocorre quando o homem não é capaz de obter/conservar uma ereção de qualidade para levar a cabo uma conexão de coito; e a impotência secundária, como aquela ereção dissipada sem a reação ejaculatória associada. A ejaculação prematura e a incapacidade ejaculatória são também disfunções sexuais.

${ }^{23}$ MASTERS e JOHNSON, 1976, p. 197, grifos meus.
Para a mulher com disfunção sexual, a segurança de uma relação criada entre o homem e mulher, identificação real com o parceiro masculino e expressão de reação emocional mútuas são de interesse vital - primeiro, para garantir um sistema de valor sexual positivamente orientado e segundo, na promoção de funcionamento sexual eficaz. Essas seguranças sociais e sexuais não podem ser criadas no curto período de tempo disponível durante a fase crítica do programa terapêutico. Por essas razões, o uso de parceiro sub-rogado do sexo masculino, no tratamento de mulheres solteiras com disfunção sexual, foi considerado contra-indicado. ${ }^{21}$

Esta não é única passagem onde o casal M\&J indica a existência de um duplo essencialismo biológico: de um lado, uma certa naturalização da sexualidade do homem e, de outro, a emotividade feminina. Nesse mesmo pensar, se em alguns trechos valoriza-se o clímax orgásmico da muIher, em outros se detecta uma visão de mulher submissa, subserviente e passiva em relação aos interesses e problemas sexuais masculinos, ${ }^{22}$ como neste longo trecho no segundo relatório:

Naturalmente, a maioria das esposas não sonharia em debater publicamente a insuficiência sexual dos seus casamentos. Por inúmeras razões, preferem manterse caladas. Talvez sintam que a disfunção do marido tem origem na sua própria falta de atrativo físico, ou pelo menos seja por ela aumentada, ou que elas forcem essa insuficiência pela própria falta de competência na função sexual. A maioria das mulheres se identifica de todo com a insuficiência sexual do marido, e sofre com isso. Elas sentem ternura e simpatia pelo seu evidente fracasso no leito conjugal. Então, por inúmeras razões, a maioria das mulheres não sonharia em discutir a disfunção sexual do marido, ainda que com sua amiga mais íntima. Mas a maioria das mulheres, quer acusem publicamente ou suportem em silêncio, não compreende até onde influenciaram diretamente a insuficiência sexual do marido. ${ }^{23}$

Pode-se confirmar ainda, através desta passagem, a defesa do casal Masters \& Johnson em prol do casamento monogâmico e a insistência na manutenção secreta das frustrações sexuais, posteriormente submetidas à reversão terapêutica proposta por eles. A cumplicidade da mulher em relação ao problema sexual do marido será a chave para a atribuição da disfunção sexual ao casal, como unidade conjugal.

No capítulo destinado à disfunção orgásmica são abordadas questões conceituais, científicas e influências dominantes inibitórias, mas M\&J apontam a presença de 
${ }^{24}$ MASTERS e JOHNSON, 1976.

${ }^{25}$ MASTERS e JOHNSON, 1976, p. 216, grifos meus. grandes obstáculos sobre o tópico pela tendência de restringir a compreensão definitiva da função sexual feminina. A disfunção orgásmica da mulher está subdividida em dois tipos: a disfunção orgásmica primária, caracterizada por uma carência de consecução orgásmica durante toda a existência; e a circunstancial, no caso de a mulher ter experimentado o orgasmo pelo menos uma vez, independentemente de ser induzido por manipulação própria ou do cônjuge. ${ }^{24}$ Apesar de, nesse contexto, identificarem a natureza da reação sexual feminina como alvo de inúmeras interpretações, M\&J alegam, por outro lado, que $95 \%$ desses estudos foram elaborados por homens, levando a tendenciosidades, defensivas e preconceitos masculinos.

É necessário um estudo separado da sexualidade feminina, primeiro porque o papel atribuído à componente funcional da identidade sexual da mulher raramente recebe o valor socialmente posto em vigor e concedido à sexualidade masculina. Embora $o$ paralelo entre os sexos quanto à função fisiológica tenha obtido aceitação geral, o conceito de que o homem e a mulher também podem compartilhar de necessidades psicossociais quase idênticas para a função sexual efetiva provoca o protesto esperado. ${ }^{25}$

Na exposição do relatório, a forma como são apresentados os casos que sofreram tratamento inclui uma breve descrição de alguns problemas e suas soluções, figuras ilustrativas de anatomia ou de posições sexuais e tabelas com os dados estatísticos.

Como registro significativo, os resultados apresentados a seguir são referentes ao índice de fracasso no tratamento da queixa, ou seja, em leitura inversa, o casal Masters \& Johnson relata o potencial de sucesso de seus procedimentos terapêuticos nas unidades conjugais, após submetidas ao tratamento:

- 40,6\% dos homens mantiveram impotência primária;

- $26 \%$ dos homens mantiveram impotência secundária;

- 2,7\% dos homens mantiveram ejaculação prematura;

- $17,6 \%$ dos homens mantiveram incapacidade orgásmica;

- 16,6\% das mulheres mantiveram disfunção orgásmica primária;

- 22,8\% das mulheres mantiveram disfunção orgásmica circunstancial;

- 9,1\% das mulheres mantiveram insuficiência orgásmica masturbatória; 
${ }^{26}$ Masters \& Johnson consideram idoso o homem ou mulher com idade acima de 50 anos (rever nota 15).

${ }^{27}$ MASTERS e JOHNSON, 1976, p. 380

${ }^{28}$ MASTERS e JOHNSON, 1976, p. 364 , grifos meus.
- 19,9\% das mulheres mantiveram insuficiência orgásmi-ca no coito;

- $37,5 \%$ das mulheres mantiveram insuficiência fortuita;

- $30,3 \%$ de homens e mulheres idosos ${ }^{26}$ permaneceram com suas disfunções sexuais.

No capítulo final do seu relatório, M\&J fornecem a estatística do programa das suas 510 unidades conjugais e 57 unidades simples que compuseram o segmento de pesquisa clínica, representando, segundo suas palavras, uma população altamente seletiva. Mesmo estando inclusos nesse grupo os resultados do acompanhamento subsequente quinquenal entre 1959 e 1964, é fornecido um sumário do índice de fracassos com as 790 unidades conjugais originais de cobertura total do programa, em 11 anos de experiência.

Contudo, vale dizer, para M\&J "esse relatório é apenas um resultado objetivo sugerido, e não um resultado objetivo estatisticamente seguro". ${ }^{27}$ Suas considerações sobre as estatísticas específicas foram fatores de avaliação baseados apenas do ponto de vista de índices de fracassos no tratamento da disfunção sexual.

As reivindicações de confiança estatística no tratamento psicoterapêutico bem sucedido não podem ser feitas, e não deveriam sê-lo, sem equívocos. Pois quem está qualificado para definir com certeza o êxito clínico de qualquer empreendimento psicoterapêutico? Os terapeutas? Eles têm, inevitavelmente, preconceitos positivos. O paciente? Este tem preconceitos positivos ou negativos. O estatístico? Excesso de variáveis. [...] Com a avaliação dos critérios subjetivos apresentados nos termos mais estritos como índice de fracasso, esse padrão pode, certamente, ser aplicado irrestritamente a programas como os representados neste relatório. Se os índices de fracasso dessa pesquisa clínica não podem, no futuro, ser reduzidos por outros programas de pesquisa objetivamente controlados, então haverá pouca evidência de progresso clínico ininterrupto no tratamento da insuficiência humana pelas profissões médica e/ou behaviorista. ${ }^{28}$

Detecta-se nesta passagem do relatório M\&J uma preocupação com a confiança estatística, considerando a estatística do fracasso como um elemento reprodutivamente positivo. O enfoque nesse sentido não é de interação entre variáveis, e sim de os esforços de pesquisas futuras serem para igualar ou melhorar os índices estatísticos de qualquer programa clínico similar.

Como último registro, nos cinco primeiros anos do programa, de 1959 a 1964, nenhum paciente pagou pelo 
${ }^{29}$ MASTERS e JOHNSON, 1976, p. 368-369, grifos meus. tratamento clínico; entretanto, nos seis anos seguintes, instituiu-se uma cobrança percentual do tratamento. Como foi salientado anteriormente, Masters \& Johnson afirmam que 0 segmento da pesquisa clínica representa uma população altamente seletiva.

\begin{abstract}
Existem outros fatores sociológicos que influenciam a nítida seletividade do encaminhamento de pacientes. A queixa específica de disfunção sexual raramente aparece, em qualquer centro de tratamento à disposição, de pacientes de renda baixa ou de camada social inferior. Se existe número infinitamente menor de disfunção sexual nesse nível social, como outros têm sugerido, ou se ainda existe, nesse nível social, uma hesitação masculina ou mesmo rejeição de oportunidade para buscar alívio de disfunção sexual ou permitir que seu cônjuge feminino tenha esse alívio, ainda não ficou estabelecido. ${ }^{29}$
\end{abstract}

Nesta citação, M\&J deixam em aberto um grande flanco de vulnerabilidade de sua pesquisa, pois, embora admitam a alta seletividade de sua população, pretensiosamente inferem que a queixa específica de disfunção sexual raramente acontece em camadas de baixa renda e vão além, apresentando hipóteses não confirmadas como, por exemplo, caso ocorra, seja devido à rejeição do homem em procurar ajuda psicoterapêutica para sua disfunção. Aliase como outra hipótese a rejeição do marido em permitir à esposa procurar alívio ou ajuda, situação de subordinação que as feministas irão incluir nas suas reivindicações pelos direitos das mulheres.

\section{N O que se falou sobre os relatórios Masters \& Johnson}

Os relatórios do médico William Masters e da psicóloga Virginia Johnson, talvez por suas origens de formação, pelos espaços prestigiados de onde falaram, pelo momento histórico (final dos anos 60) ou porque cercaram seus estudos de experimentação laboratorial científica, não foram tão atacados quanto os seus antecessores, os relatórios Kinsey, e seus sucessores discursivos, os relatórios Hite.

Nas referências encontradas sobre a produção de M\&J, as maiores críticas destinaram-se ao caráter tipicamente técnico de suas conclusões, a uma sobrevalorização do orgasmo e à promoção pessoal de um tratamento modelar das disfunções sexuais.

O historiador Gerard Vincent, no capítulo "O corpo e o enigma sexual", em História da vida privada. Da Primeira Guerra a nossos dias, volume 5, da coleção dirigida por Philippe Ariès e Georges Duby, apresenta uma síntese da 
30 VINCENT, 1992, p. 352, grifos meus.

${ }^{31}$ BÉJIN, 1987a.

32 BÉJIN, 1987b.

${ }^{33[13]}$ A sexologia do século XIX estava preocupada com quadros psicopatológicos da sexualidade (doenças venéreas, aberrações e degenerescências); mais centrada, portanto, em uma nosografia do que numa terapêutica. busca do entendimento sexual durante o século XX, focando na caçada ao orgasmo uma das práticas dos sexologistas. Para Vincent, foi depois da Segunda Guerra que a sexologia se tornou um ramo legítimo das ciências humanas, mas as mudanças ocorridas partiram da mulher:

O que é historicamente novo é o discurso feminino que expressa sua sexualidade e manifesta suas reclamações. Masters \& Johnson nos relatam que, nos anos 50 , seus pacientes eram homens preocupados com seus fracassos: impotência, ejaculação precoce, etc. A partir dos anos 60 , um número crescente de mulheres passou a consultá-los pela dificuldade ou incapacidade de atingir o orgasmo. A partir dos anos 70 , ainda segundo os mesmos autores, surge uma nova ansiedade que eles definem como "a de não ter a possibilidade fisiológica da eficácia", o que significa que, resolvidos os problemas psíquicos, resta $o$ das capacidades sexuais muito desiguais entre os indivíduos. O casal, agora, deve se estruturar em torno da harmonia sexual. ${ }^{30}$

Numa linha de pensamento mais crítica, André Béjin, em dois artigos, "Crepúsculo dos psicanalistas, manhã dos sexólogos" 31 e "O poder dos sexólogos e a democracia sexual", ${ }^{32}$ ambos publicados no livro Sexualidades ocidentais, discorre sobre um crescente processo de racionalização da sexualidade no século XX, em que a sexologia tenderá a ser somente uma "orgasmologia" e as terapias de sexualidade, "orgasmoterapias". Segundo ele, põem-se de lado os "desvios" e as "aberrações" ${ }^{3[13]}$ e coloca-se no centro outra norma, a norma do orgasmo ideal, a injunção da produtividade orgásmica e a regra da reciprocidade do gozo. $O$ alvo do sexólogo, o orgasmólogo, é a disfunção. Para Béjin, as terapias de Masters \& Johnson constituem o paradigma das orgasmoterapias, baseadas numa concepção nitidamente behaviorista de disfunção sexual, resultante de aprendizagens inadequadas.

[...] o orgasmólogo aparece como um programador. E isso em dois planos. No plano ético: ele coloca e define uma norma simples, o imperativo orgásmico (não mais o direito ao orgasmo, mas o dever do orgasmo), e as condições para a aplicação desta norma, que constituem no respeito dos princípios da "democracia sexual" (contrato sexual, o toma lá-dá cá do gozo...). No plano técnico: ele ensina a seus pacientes a autodisciplina orgásmica (por exemplo, a melhor técnica táctil para se chegar a esse objetivo supremo, o orgasmo simultâneo), que deverá ser posta à prova dentro do quadro de um regime explicam Masters e Johnson - de "liberdade vigiada". O estabelecimento de um tal controle com finalidade 
${ }^{34}$ BÉJIN, 1987a, p. 231, grifos meus em itálico, grifos do autor em negrito.

${ }^{35}$ GAGNON e SIMON, 1973.

${ }^{36}$ BOZON, 2004, p. 52, grifos meus em itálico, grifos do autor em negrito.
${ }^{37}$ BRUCKNER e FINKIELKRAUT, 1981, p. 132. pedagógica favorece um aprofundamento do domínio pedagógico. ${ }^{34}$

Numa análise crítica semelhante, fazendo inclusive referências a Béjin, o sociólogo Michel Bozon atribui a Masters \& Johnson o estabelecimento de uma sexologia terapêutica destinada a casais que tenham assimilado scripts sexuais inadequados, fazendo com o uso dessa terminologia uma alusão à teoria dos scripts sexuais de John Gagnon e William Simon, descrita em Sexual Conduct, editada em 1973: ${ }^{35}$

[...] o médico William Masters e a psicóloga Virginia Johnson fundaram, nos anos 60 , uma sexologia terapêutica que teria inúmeros adeptos, propondo uma norma mais restritiva para a seleção sexual, sem qualquer referência à reprodução. A sua originalidade foi terem-se fundamentado, inicialmente, em uma observação em laboratório das reações fisiológicas de parceiros durante relações heterossexuais capazes de levar ao orgasmo. Sua descrição dos estágios de uma relação sexual (excitação, platô, orgasmo e resolução) tornou-se clássica e estabeleceu uma norma de funcionamento sexual, fundamento da união do casal: para Masters e Johnson, a união através do prazer (pleasure bond) é a própria base do casamento. ${ }^{36}$

Para Bozon, se as terapias inspiradas em Masters \& Johnson, de um lado, proporcionaram um fortalecimento do conceito de disfunção sexual, por outro fizeram surgir outro tipo de intervenção, o medicamentoso. A gradativa medicalização da sexualidade e a patologização dos distúrbios redefiniram os conceitos, e nesse sentido a disfunção erétil passa a receber tratamento farmacológico oral. Segundo o autor, a comercialização do Viagra, a partir de 1998, colocou a ereção no centro da relação sexual e assim a demanda pelo produto "criou" a disfunção.

Os escritores Pascal Bruckner e Alain Finkielkraut, de A nova desordem amorosa, fazem coro aos críticos de Masters \& Johnson por estes terem elaborado um texto técnico, com uma função técnica de avaliar o orgasmo funcional da mulher.

\footnotetext{
"Quais os meios objetivos através dos quais avaliar o gozo de um parceiro?" Sem mal-entendidos: do parceiro feminino (uma vez que o sêmen masculino é um índice sem ambigüidades). Em outras palavras: como não ser enganado pela mulher, como saber se ela não está simulando, imitando um processo que não está sentindo nem de longe? Velho, antiqüíssimo desejo de clareza, de legitimidade sem lacunas. (Sabe-se que toda a sexologia atual, e especialmente os trabalhos de Masters e Johnson, não têm outra finalidade além de satisfazer essa louca vontade de transparência.) ${ }^{37}$
} 
${ }^{38}$ ROBINSON, 1977, p. 178, grifos meus.
O historiador Paul Robinson, em A modernização do sexo: ensaios sobre Ellis, Kinsey, Masters \& Johnson, publicado em 1976, faz uma análise balanceada, entre méritos e deméritos, destes três autores da sexualidade moderna, integrantes influentes de uma nova história intelectual depois de Freud: a história dos sexologistas. Em relação aos estudos de Masters \& Johnson, Robinson descreve-os como totalmente de orientação matrimonial, biologicamente funcional e defensores do casal e casamento monogâmico. Acusa a população pesquisada de irrepresentativa na composição social, na distribuição etária e nas tendências sexuais. Por outro lado, elogia M\&J por terem tomado posições genuinamente progressistas com relação às mulheres, à masturbação feminina e à velhice. Segundo o historiador,

As feministas acolheram Masters \& Johnson com o mesmo entusiasmo com que os homossexuais o fizeram com Kinsey. Seu entusiasmo não foi imerecido. Human sexual response e, até certo ponto, Human sexual inadequacy contribuíram para acelerar a causa dos direitos sexuais das mulheres mais do que outra obra escrita no último quarto do século. [...] Uma das indicações mais importantes do feminismo de Masters \& Johnson é a sua recusa em tratar a sexualidade feminina simplesmente como um reflexo da sexualidade masculina. ${ }^{38}$

Em consonância a Michel Foucault, pode-se extrair deste recorte um exemplo confirmatório das relações de exterioridade entre os discursos e as práticas extradiscursivas (práticas sociais, econômicas e políticas): discursos mobilizando movimentos, contramovimentos e contradiscursos. Nesses domínios sem limites rígidos desenvolveram-se algumas transformações nas relações entre o masculino e o feminino a partir das décadas de 60 e 70, mas cujos processos retrocedem às décadas anteriores, numa teia de relações de poder e relações de saber, articulada em história carregada de permanências (continuidades) e rupturas (descontinuidades), mediatizadas por políticas gerais de verdades científicas.

\section{Pontos finais...}

Os relatórios Masters \& Johnson (assim como os relatórios Kinsey e os relatórios Shere Hite) emergiram num contexto histórico e social com status de verdade científica. Apresentaram uma distinção da ordem de gênero, sexualidade feminina e sexualidade masculina, ora com naturalizações sendo reafirmadas, ora com investimentos na produção de tipos idealizados de homens e mulheres sexuais. 
${ }^{39}$ FOUCAULT, 1988.
Ancoramos nossa fundamentação em Michel Foucault, principalmente em suas elaborações presentes em História da sexualidade I. A vontade de saber ${ }^{39}$ e sua crítica ao modo como a sociedade ocidental situa a sexualidade: na configuração de uma scientia sexualis (ciência sexual) desenvolvida para dizer uma verdade no sexo, verdade entendida como construtora de normatividades (pelas formas de saber) e normalidades (pelas forças de poder).

Nesse sentido, os relatórios Masters \& Johnson, através de questionários, enquetes, entrevistas, narrativas e outras técnicas de observação, descreveram comportamentos íntimos sexuais, relataram privacidades, expuseram medos, receios, em suma: apresentaram "novas" possibilidades de descobertas e explicações sexológicas. Os depoimentos, os relatos, as descrições minuciosas sobre o corpo, reações físicas, zonas erógenas, preferências sexuais, segredos, os desejos e as fantasias sexuais, insistentemente citadas e referenciadas, são mentiras ou são verdades? São verdades produzidas historicamente, a partir das contribuições de diversas ciências, com "especialistas" legitimando as informações distribuídas e divulgadas através de formas discursivas.

Mas é na ânsia de respostas verdadeiras que emerge a insistente pergunta: "Sou normal?" "Sou anormal?" O que é normal para quem pergunta? Será que bastaria ouvir de um "especialista" a resposta "você não é anormal!" ou ouvir "isto não é doença!"? As estranhezas ou as discrepâncias de comportamento sexual são colocadas em relação a mim ou em relação aos outros? Somos o que o outro confirma que somos? Somos o que o outro afirma que somos? A diferença entre afirmação e confirmação não é apenas de ordem semântica. Eu sou o diferente, ou os outros? Em resumo: quem é o normal? Como algo ou alguém é considerado anormal?

Nessas escalas classificatórias de (a)normalidade, o recurso à estatística é uma prática comum e pretensamente legitimadora de verdade científica. Ao ver os percentuais estatísticos num livro "científico", o enquadramento comparativo é automático: estando nos $70 \%$ ou nos $30 \%$, é o número que me avaliará, é um "diagnóstico estatístico", não é um diagnóstico clínico, cuja mediação (pela média numérica!) é relatada pelos participantes das enquetes, logo, os outros. Se estiver na maioria, tudo bem, sou normal; caso contrário, tendo esse (pré/pseudo)diagnóstico estatístico (científico) como referência, procurarei (se puder) um especialista para confirmação através de um diagnóstico clínico (científico). É a prática real da normalização que determina o conceito de normal e é essa a possibilidade de um conceito ser incorporado como um preceito. Nessa teia de jogos numéricoestatísticos (verdadeiros!?), as pessoas confundem dados 
(descrições) com valores (apreciações), quantificações com qualificações, as normas com os normais.

Os relatórios são ainda, contemporaneamente, fontes validadas e convalidadas pelo campo da sexologia, da medicina e da psicoterapia sexual, e é por esse aspecto que seus usos práticos se colocam como questões do presente a serem problematizadas.

Nessa linha de raciocínio histórico problematizador, a sexualidade contemporânea, bem como as suas "instâncias terapêuticas", clínicas ou não, se veem diante de ampliações e rearranjos das questões nos campos discursivos e extradiscursivos, como, por exemplo, outras configurações familiares, as questões de gênero e diversidade, a multiplicidade das sexualidades, enfim, um espectro sexual com matizes sem fronteiras definidas que fazem repensar os rígidos enquadramentos normatizadores e normalizadores das tramas do poder-saber centrados em conjugalidades e valores monogâmicos, heterossexuais e machistas.

\section{Referências bibliográficas}

BÉJIN, André. "Crepúsculo dos psicanalistas, manhã dos sexólogos". In: ARIÉS, Philippe; BÉJIN, André (Orgs.). Sexualidades ocidentais - contribuições para a história e para a sociologia da sexualidade. 3. ed. São Paulo: Brasiliense, 1987a. p. 210-235.

"O poder dos sexólogos e a democracia sexual". In: ARIÉS, Philippe; BÉJIN, André (Orgs.). Sexualidades ocidentais - contribuições para a história e para a sociologia da sexualidade. 3. ed. São Paulo: Brasiliense, 1987b. p. 236-254.

BOZON, Michel. Sociologia da sexualidade. Rio de Janeiro: Editora FGV, 2004.

BRUCKNER, Pascal; FINKIELKRAUT, Alain. A nova desordem amorosa. São Paulo: Brasiliense, 1981.

FOUCAULT, Michel. História da sexualidade I. A vontade de saber. Rio de Janeiro: Edições Graal, 1988.

GAGNON, John; SIMON, William. Sexual Conduct. Chicago, USA: Aldine Publishing Company, 1973.

MASTERS, William; JOHNSON, Virginia. O vínculo do prazer. Rio de Janeiro: Record, 1975.

A incompetência sexual: suas causas, seu tratamento.

2. ed. Rio de Janeiro: Civilização Brasileira, 1976.

. Homossexualidade em perspectiva. Porto Alegre: Artes Médicas: 1979.

. A conduta sexual humana. 4. ed. São Paulo: Civilização Brasileira, 1981.

. A resposta sexual humana. São Paulo: Roca, 1984. 
MASTERS, William; JOHNSON, Virginia; KOLODNY, Robert. Manual de medicina sexual. São Paulo: Manole, 1982. 1997.

. Heterossexualidade. Rio de Janeiro: Bertrand Brasil,

REICH, Wilhelm. O combate sexual da juventude. São Paulo: Edições Epopéia, 1986.

. A função do orgasmo. São Paulo: Brasiliense, 1995.

ROBINSON, Paul. A modernização do sexo. Rio de Janeiro: Civilização Brasileira, 1977.

VINCENT, Gerard. "Uma história do segredo?". In: PROST, Antoine; VINCENT, Gerard. História da vida privada 5. Da Primeira Guerra a nossos dias. São Paulo: Companhia das Letras, 1992. p. 155-389.

[Recebido em fevereiro de 2009 e aceito para publicação em novembro de 2009]

\section{The Masters \& Johnson's Reports: Gender and the Sexual Psychotherapy Practices as of the 1970s}

Abstract: This work is the result of an analysis on the Masters \& Johnson's Reports, originally published in 1966 (Human Sexual Response) and 1970 (The Human Sexual Inadequacy). The reports investigated, produced in the United States and spread worldwide, were prepared based on a careful, scientific investigation of the physiologic and anatomic responses of male and female sexuality. The authors used the results to formulate techniques and treatment in sexual therapy, which are so far in use by professionals in the clinical area. The Masters \& Johnson's reports came with the proposal of filling the medical, physiological and psychological gaps left by the behaviorist statistics research by Alfred Kinsey (1948 and 1953). M\&J's work defends openly the heterosexual monogamist marriage, with elaborations mingled with gender questions. From the theoretical tools by Michel Foucault, it is possible to observe that they are examples of the scientia sexualis practice, which tries to institute a truth in sex and of sex.

Key Words: Masters \& Johnson Reports; Sexuality; Sexual Therapy. 